\title{
Pulmonary Hypertension and Pregnancy: Management and Outcome
}

\author{
Dror Rosengarten and Mordechai R Kramer* \\ Institute of Pulmonology, Rabin Medical Center, BeilinsonCampus, Petah Tiqwa, Sackler Faculty of Medicine, Tel Aviv University, Israel
}

\begin{abstract}
Pulmonary Arterial Hypertension (PAH) is a disorder defined by elevated mean pulmonary arterial pressure. PAH can be idiopathic or associated with a variety of medical conditions such as scleroderma, congenital heart disease, left heart failure, lung disease or chronic pulmonary thromboembolism. This progressive disease can cause severe right heart failure and death.

Normal physiologic changes that occur during pregnancy may produce fatal consequences in PAH patients. Current guidelines recommend that pregnancy be avoided or terminated early in women with PAH. During the past decade, new advanced therapies for PAH have emerged leading to reports of successful pregnancies in patients with pulmonary hypertension. Substantial risk still exist, and current recommendations have not changed; nevertheless, in selected cases, if a patient insists on continuing with the pregnancy despite full awareness of the risks, an intensive treatment approach should be implemented in experiences medical centers to improve the outcome. This review article will focus on the pathophysiology of $\mathrm{PAH}$ in pregnancy and appropriate management during pregnancy, delivery and the post-partum period.
\end{abstract}

Keywords: PAH: Pulmonary Arterial Hypertension; RHC: Right Heart Catheterization; IUD: Intrauterine Device; NO: Nitric Oxide; IPAH: Idiopathic Pulmonary Arterial Hypertension; CHD: Congenital Heart Disease; OPH: Other causes of Pulmonary Hypertension; CS: Caesarean Section; PC: Prostacyclin; NO: Nitric Oxide; S: Sildenafil; CCB: Calcium Channel Blockers

\section{Introduction}

Pulmonary Arterial Hypertension (PAH) is a disorder defined by measuring mean pulmonary arterial pressure above $25 \mathrm{mmHg}$ on Right Heart Catheterization (RHC). This disorder is characterized by rapid right heart failure and death if not adequately treated. According to the latest classification there are about 40 different diseases which can result in pulmonary hypertension [1]. PAH can be idiopathic or can be associated with a variety of medical conditions such as scleroderma, congenital heart disease, left heart failure, lung disease or chronic pulmonary thromboembolism. The average age at diagnosis is 37 years and female to male ratio is about 1.7:1, therefore, the disease is frequently encountered in younger females. Female patients with PAH may become pregnant and occasionally the first clinical manifestations of PAH are seen during the course of pregnancy. It is well known that pregnancy poses an immense risk to females with PAH and maternal mortality reached 56\% in early reports published between 1978 and 1996, [2] and even in recent reports mortality rate remains unacceptably high (25-30\%) [3]. Therefore, current guidelines recommend that pregnancy be avoided or terminated early in women with PAH [4].

In recent years enormous development has been made in the field of PAH and many potent new medications are now available. Improvement in quality of life and prognosis led to the hope that females with PAH could become pregnant with better outcomes than previously. A retrospective comparison of the outcomes of published cases demonstrated a decline in maternal mortality of parturient with $\mathrm{PAH}$ in recent years [5].

However even with best new medical therapy, the outcome is not satisfactory. Often patients with $\mathrm{PAH}$ decide to continue pregnancy despite medical recommendation and introduce a complex management challenge for the clinician. This review article will discuss the pathophysiology of $\mathrm{PAH}$ in pregnant patients and the appropriate management during pregnancy, delivery and the post-partum period. We present in this article the current clinical practice based on a systematic literature review and on our own clinical experience.

\section{Physiological Changes during Pregnancy}

Significant cardiovascular physiologic changes occur during pregnancy. Blood volume, heart rate, cardiac output and cardiac consumption gradually increase from the fifth week until the end of pregnancy. These parameters remain elevated for a few weeks after delivery. Blood volume can increase even to $50 \%$ above the normal volume in a non-pregnant patient [6]. Furthermore, during delivery, about $500 \mathrm{ml}$ of uterine blood is diverted to maternal circulation with every uterine contraction [7]. In healthy individuals, pulmonary vascular resistance reduces, thus, this massive volume load to the pulmonary circulation does not cause elevation of pulmonary pressure. In contrast, in patients with $\mathrm{PAH}$, high and fixed pulmonary vascular resistance is a main feature obviously related with limitation of adjustment of resistance; both impair adaptation to an increasing blood volume. Therefore, the pressure presented to the right ventricle increases as the pregnancy progresses.

In patients with Eisenmenger syndrome, elevated pulmonary pressure increases right to left shunt and worsened hypoxic vasoconstriction thus further increasing the pulmonary vascular resistance [8]. Furthermore, pregnancy is a condition characterized by increased risk of thrombosis and pulmonary embolism [9], of course, an event of pulmonary embolism in a patient with PAH can cause right ventricle failure and can lead to death.

\section{Symptoms and Signs of PAH in Pregnancy}

Presenting symptoms in patients with $\mathrm{PAH}$ are not specific to this situation, characterized by shortness of breath, weakness, fatigue, chest pain, syncope and abdominal discomfort [10]. Some of these

*Corresponding author: Mordechai R Kramer MD, Pulmonary Institute, Rabin Medical Center, Beilinson Campus, Petah Tiqwa 49100, Israel, Tel: +972-39377221; Fax: +972-3-9242091; E-mail: kremerm@clalit.org.il

Received November 05, 2013; Accepted November 22, 2013; Published November 25, 2013

Citation: Rosengarten D, Kramer MR (2013) Pulmonary Hypertension and Pregnancy: Management and Outcome. J Pulmon Resp Med S4: 004. doi:10.4172/2161-105X.S4-004

Copyright: $\odot 2013$ Rosengarten D, et al. This is an open-access article distributed under the terms of the Creative Commons Attribution License, which permits unrestricted use, distribution, and reproduction in any medium, provided the original author and source are credited. 
symptoms are very common in pregnancy as well as in many other situations. Therefore, physicians must look for these symptoms and assess them carefully and refer the woman for echocardiography whenever there is a suspicion of PAH. Assessment of pulmonary pressure by echocardiography has a strong correlation to RHC and it is recommended as screening test [11]. RHC is required for a definite diagnosis of $\mathrm{PAH}$, to determine the severity of the disease, to assess the prognosis and to select the appropriate treatment and therefore it is mandatory in any case where PAH is suspected by echocardiography.

According to $\mathrm{PAH}$ guidelines during follow-up patients often have to repeat RHC to monitor the response to treatment and in cases of unexplained clinical deterioration [4]. RHC is a safe procedure with a very low risk. Survey of 7218 catheterizations reported complications only in $1.1 \%$ of the cases. The major complications were hematomas or pneumothorax which were treated without significant consequences [12], Thus, RHC should be performed in any pregnant woman with suspected PAH.

\section{Mortality Risk for Mother and Fetus in a Patient with PAH}

In the past, the mortality risk in pregnant patients PAH was considered very high. Retrospective review of the literature from 1978 to 1996 found reports of 125 pregnancies in PAH patients. Mortality in this series was $30 \%$ in patients with primary $\mathrm{PAH}, 36 \%$ in patients with pulmonary hypertension associated with Eisenmenger syndrome and $56 \%$ in patients with $\mathrm{PAH}$ associated with other conditions such as anorexigen use, liver disease, connective tissue diseases and pulmonary thrombo embolic disease. Recent progress has been made in the treatment of pulmonary hypertension, and many potent new medications are now available, giving hope to reduce the maternal mortality rate. Indeed, a review was made from 1997 to 2007 which followed 73 patients, and mortality was significantly lower compared with the previous survey: $17 \%$ of patients with primary pulmonary hypertension, $28 \%$ of patients with pulmonary hypertension associated with Eisenmenger syndrome and 33\% in patients with $\mathrm{PAH}$ associated with other conditions. In this series most of the patients (72\%) received a specific PAH therapy [5]. Most of the deaths occurred in proximity to delivery, especially in the first month after birth. A sharp increase in heart rate, cardiac output and oxygen consumption of the heart muscle causes hemodynamic stress which reaches its peak at birth and can cause failure of the right ventricle and death. Therefore, the time of birth and the postpartum period are the most dangerous. These series show that although mortality decreased significantly with the availability of new treatments for $\mathrm{PAH}$, maternal mortality rates remain very high.

The comparison between the series is limited. New vasodilators were not available previously and even in the later series, $28 \%$ of patients were not treated with them. This retrospective series has been collected from different centers, making it impossible to determine that the quality of care was equal. Especially noteworthy is the time factor: we can assume that cesarean section procedures, intensive-care unit surveillance and treatment of high-risk pregnancy improved from 1978 until 2007.

The rate of fetal mortality was also high and reached7\% to $13 \%$ in various reports. Mortality probably is due to intrauterine growth retardation, maternal distress and premature birth. Data on morbidity and morbidity in the surviving fetuses were not published.

\section{Treatment Approach to the Pregnant Patient with PAH Birth control}

Emphasizing the potential risk of pregnancy for patients with $\mathrm{PAH}$ and discussing methods of birth control is crucial. There is no consensus regarding the preferred method of contraception. Contraception barriers are easy to use and safe but without optimal efficacy, and therefore should be used only temporarily. The advantages of the Intrauterine Device (IUD) with progesterone (reliability, simplicity, compliance, few contraindications and interactions, possibility of use in the nulliparous patient, reimbursement by the healthcare system) make it a good contraceptive choice in these circumstances [13] Permanent methods such as tubal ligation can also be recommended. Oral contraceptives are a good option for prevention; nevertheless, pills containing estrogen increase the risk of venous thrombotic events while progesterone based pills can interfere with warfarin balance. We advise that the doctor will discuss the various options with the patient and choose the appropriate option in each case [14]. Considering the high risk to the mother and the early termination of pregnancy is recommended [3]. However, many women find it difficult to accept this recommendation particularly as the pregnancy progresses.

Late termination of pregnancy requires further skills and a multidisciplinary team and therefore, referral to medical centers with experience in treating $\mathrm{PAH}$, high-risk pregnancy, intensive care and anesthesia is recommended $[15,16]$.

\section{Anticoagulation and oxygen therapy}

Thrombotic arteriopathy is an important pathophysiological feature of PAH and may alter the progression and prognosis of PAH patients [17]. According to the guidelines, anticoagulant treatment is recommended in any patient with idiopathic $\mathrm{PAH}$, heritable $\mathrm{PAH}$, $\mathrm{PAH}$ due to use of anorexigens (Recommendation grade IIA) and PAH associated with other conditions (Recommendation grade IIB). Pregnant patients have an increased risk of deep vein thrombosis that can cause pulmonary embolism and therefore the common practice is to give anticoagulation therapy although no prospective studies have proved the efficacy of this treatment. Anticoagulation therapy was used in $52-68 \%$ of patients in previous series [18]. Warfarin is known to be teratogenic, therefore, subcutaneous injection of Enoxaparin (1 $\mathrm{mg} / \mathrm{kg}$ twice daily) is recommended. Oxygen therapy should be given to patients suffering from hypoxia and diuretic therapy should be administrating if signs of right heart failure develops.

\section{Specific treatment for PAH}

There is a small group (about 12\%) of patients with a vasoreactive form of pulmonary hypertension in whom haemodynamics demonstrate pulmonary pressure decrease after vasodilator administration. (Vasoreactivity is define by a decrease of the mean pulmonary pressure of at least $10 \mathrm{mmHg}$ to less than $40 \mathrm{mmHg}$ ) Calcium channel blocker at high doses is the recommended treatment for this group [19]. This group has a good prognosis and uncomplicated course of pregnancy was reported recently [18].

PAH specific vasodilator treatment is divided into three groups by different mechanisms [20].

Endothelin receptor blockers are potent vasodilator drugs taken orally. Currently available drugs are Bosentan, Ambrisentan and Macitentan [21]. All drugs in this group are considered to be teratogenic (Category $\mathrm{X}$ ) and therefore if a $\mathrm{PAH}$ patient becomes pregnant, discontinuation of this drug is mandatory. 
NO (Nitric Oxide) - NO causes vasodilatation and anti-proliferation of the pulmonary vasculature by activating cGMP. This effect is inhibited by PDE5 (Phosphodiesterase Type 5) activity and therefore PDE5 inhibitors increase the concentration of cGMP and thus encourage the activity of NO and cause vasodilatation of the pulmonary vasculature. Currently available drugs are Sildenafil and Tadalafil, taken orally [22]. These drugs can be given during pregnancy (Category B). During labor and hospitalization continuous inhaled NO can also be used to lower the pulmonary pressure, but this treatment is not feasible outside of the hospital.

Prostacyclin pathway - is the most potent route with several administration options: continuous intra-venous therapy (Epoprostenol or Treprostinil), sub-cutaneous pump (Treprostinil) or inhalation (Iloprost) [23]. These drugs can be given during pregnancy (Epoprostenol and Treprostinil - Category B and Iloprost - Category C).

Combinations of medications with different mechanisms are recommended if the patient deteriorates with a single drug regimen [24].

Approach to patients with $\mathrm{PAH}$ is based on large qualitative studies and discussed extensively in clinical guidelines [4,25] However, treatment of $\mathrm{PAH}$ in pregnant patients has no acceptable guidelines for a minority of cases and the lack of studies comparing different treatments. Literature in this area is based on series reports in various medical centers treated by expert opinion. Table 1 summarizes the main reports published in this area in recent years.

\section{Recommendations Regarding the Preferred Method of Delivery}

There is controversy in the literature regarding the optimal mode of delivery; Caesarean section or normal vaginal delivery [26]. The benefits of vaginal delivery are: less changes in blood volume, less bleeding, less clot formation and less risk of infection, but the disadvantages of vaginal delivery are: stress and pain periods, sympathetic increase in blood pressure and pulse rate thereby increasing the load on the right ventricle [27]. The important benefit of caesarean section is that it is performed electively under optimal conditions, thus avoiding prolonged stress and pain. It seems that in the recent series published in leading centers, the tendency is to conduct more births by caesarean sections (Table 1 ).

\section{Anesthesia}

Anesthesia should be performed by an experienced anesthesiologist early in labor to prevent an increase in cardiac output, pulmonary pressure associated with uterine contractions and pain. The mode of anesthesia to be used remains in debate with some in favour of general anesthesia and others preferring the use of regional anesthesia [28]. The advantages of regional anesthesia are: less impact on contractions of the heart and pulmonary resistance, but on the other hand there is a greater risk of bleeding than in general anesthesia [29].

\section{Postnatal care}

The majority of deaths among pregnant patients with $\mathrm{PAH}$ occurred in the peri-partum period, mainly within the first month from delivery. During delivery, both systolic and diastolic blood pressures increase markedly during contractions because of compression of the abdominal aorta by the uterus, resulting in an increase in peripheral vascular resistance. Furthermore, temporary increase in venous return due to relief of caval compression and the additional blood shifting from the contracting uterus into the systemic circulation result in additional hemodynamic stress, leading to increase pulmonary hypertension and tore fractory right heart failure. Pulmonary embolism risk also continues after delivery, therefore careful monitoring of the patient and supportive treatment is needed to prevent development of right heart failure [30].

\section{Recommended therapeutic algorithm}

Review of the clinical practice described in the recent published series in the literature is presented on Table 1. Based on these series and on the Rabin medical center experience [31], we present a recommended algorithm for diagnosis and management of pulmonary hypertension in pregnancy (Figure 1).

\section{Summary}

Development of unexplained shortness of breath in pregnant woman may be the first symptom of PAH and echocardiography must be done to rule out this option. Pregnancy carries an increased risk for patients with PAH, despite the enormous progress made in recent years in both knowledge and therapy. The usual recommendation is to avoid this dangerous situation by the intelligent use of contraceptives and termination of pregnancy as soon as feasible. Nevertheless, many recent reports indicate improved prognosis of patients who gave birth with intensive therapy and careful monitoring in medical centers with experience in this field. Accordingly, in selected cases, despite the risk, follow-up and intensive therapy by a multidisciplinary team can control pulmonary pressure during pregnancy and allow the woman to give birth safely.

\begin{tabular}{|c|c|c|c|c|c|c|}
\hline & Number & Type of delivery & Anesthesia & Medical treatment & $\begin{array}{l}\text { Maternal } \\
\text { mortality }\end{array}$ & $\begin{array}{c}\text { Fetal } \\
\text { mortality }\end{array}$ \\
\hline Bedard et al. [5] & $73 \mathrm{IPAH}=29 \mathrm{CHD}=290 \mathrm{OH}=15$ & $\begin{array}{c}\text { Vaginal 7-30\%; CS 70- } \\
93 \%\end{array}$ & $\begin{array}{l}\text { Regional } 28-67 \% \text {; } \\
\text { General } 29-43 \%\end{array}$ & $\begin{array}{l}\text { PC } 20-62 \% ; \text { NO } 24-33 \% \\
\text { S 0-14\%; CCB } 21-31 \%\end{array}$ & $17-33 \%$ & $10-13 \%$ \\
\hline Kiely et al. [15] & 10 & CS & Regional & $\begin{array}{c}\text { IV PC } 40 \% ; \text { INH PC } \\
100 \% ; \text { S } 30 \%\end{array}$ & $10 \%$ & 0 \\
\hline Smith JS et al. [32] & 5 & Vaginal $60 \%$; CS $40 \%$ & NA & IV PC $100 \%$ & 0 & 0 \\
\hline Jaïs X et al. [18] & 20 & Vaginal $5 \%$; CS 95\% & $\begin{array}{l}\text { Regional } 80 \% \\
\text { General } 20 \%\end{array}$ & $\begin{array}{c}\text { IV PC } 15 \% \text {; SC PC } 5 \% \\
\text { INH PC } 15 \% ; \text {; } 20 \% \\
\text { CCB } 40 \%\end{array}$ & $20 \%$ & $10 \%$ \\
\hline Duarte et al. [16] & 12 & CS $100 \%$ & $\begin{array}{l}\text { Regional } 66 \% \\
\text { General } 25 \%\end{array}$ & $\begin{array}{c}\text { IV PC } 41 \% ; \text { SC PC } 8 \% \\
\text { S } 33 \%\end{array}$ & $16.7 \%$ & 0 \\
\hline Rabin Medical Center [31] & 9 & CS $100 \%$ & $\begin{array}{l}\text { Regional } 20 \% \\
\text { General } 80 \%\end{array}$ & IV PC 88\%; S 55\% & $22 \%$ & 0 \\
\hline
\end{tabular}

IPAH: Idiopathic Pulmonary Arterial Hypertension; CHD: Congenital Heart Disease; OPH: Other causes of Pulmonary Hypertension; CS: Caesarean Section; PC: Prostacyclin; NO: Nitric Oxide; S: Sildenafil; CCB: Calcium Channel Blockers; NA: Not Available.

Table 1: Recent published series in the literature. 
Citation: Rosengarten D, Kramer MR (2013) Pulmonary Hypertension and Pregnancy: Management and Outcome. J Pulmon Resp Med S4: 004. doi:10.4172/2161-105X.S4-004

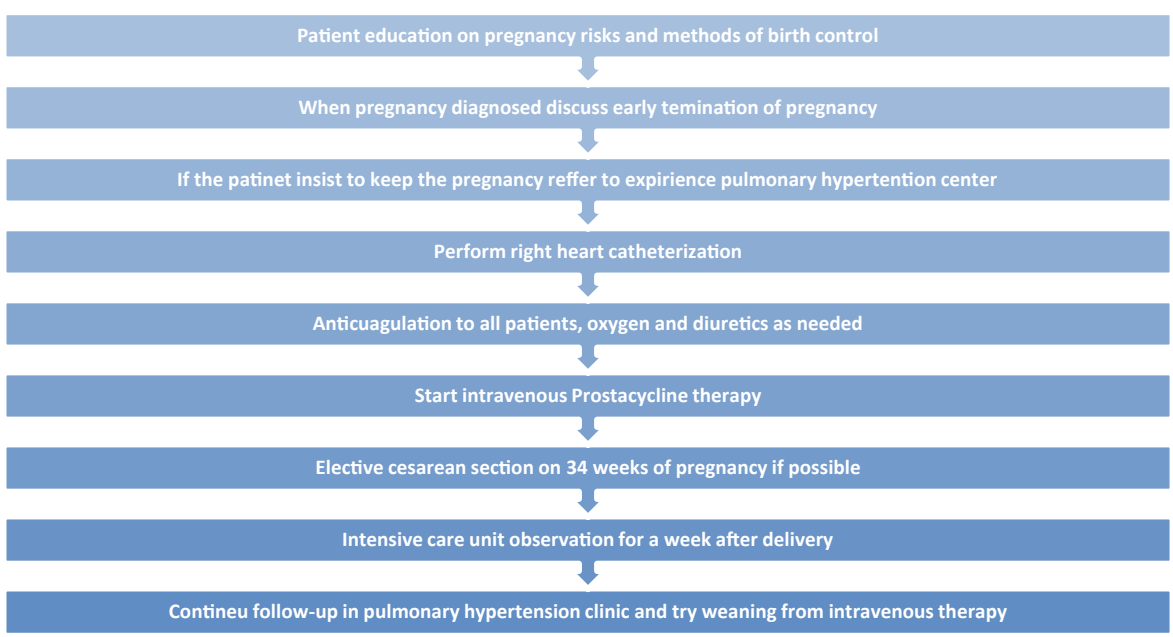

Figure 1: Approach to pulmonary hypertension in pregnancy.

\section{References}

1. Simonneau G, Robbins IM, Beghetti M, Channick RN, Delcroix M, et al. (2009) Updated clinical classification of pulmonary hypertension. J Am Coll Cardiol 54: S43-54.

2. Weiss BM, Zemp L, Seifert B, Hess OM (1998) Outcome of pulmonary vascular disease in pregnancy: a systematic overview from 1978 through 1996. J Am Coll Cardiol 31: 1650-1657.

3. Lane CR, Trow TK (2011) Pregnancy and pulmonary hypertension. Clin Chest Med 32: 165-174.

4. Task Force for Diagnosis and Treatment of Pulmonary Hypertension of European Society of Cardiology (ESC), European Respiratory Society (ERS), International Society of Heart and Lung Transplantation (ISHLT), Galiè N, Hoeper MM, et al. (2009) Guidelines for the diagnosis and treatment of pulmonary hypertension. Eur Respir J 34: 1219-1263.

5. Bédard E, Dimopoulos K, Gatzoulis MA (2009) Has there been any progress made on pregnancy outcomes among women with pulmonary arterial hypertension? Eur Heart J 30: 256-265.

6. Hegewald MJ, Crapo RO (2011) Respiratory physiology in pregnancy. Clin Chest Med 32: 1-13, vii.

7. Hunter S, Robson SC (1992) Adaptation of the maternal heart in pregnancy. $\mathrm{Br}$ Heart J 68: 540-543.

8. Warnes CA (2004) Pregnancy and pulmonary hypertension. Int J Cardiol 97: $11-13$.

9. Madden BP (2009) Pulmonary hypertension and pregnancy. Int J Obste Anesth 18: 156-164.

10. Gaine SP, Rubin LJ (1998) Primary pulmonary hypertension. Lancet 352: 719 725

11. Wylie BJ, Epps KC, Gaddipati S, Waksmonski CA (2007) Correlation of transthoracic echocardiography and right heart catheterization in pregnancy. J Perinat Med 35: 497-502.

12. Hoeper MM, Lee SH, Voswinckel R, Palazzini M, Jais X, et al. (2006) Complications of right heart catheterization procedures in patients with pulmonary hypertension in experienced centers. J Am Coll Cardiol 48: 25462552.

13. Frachon I, Gaudin SP, Jezequel C, Jaïs X, Gut-Gobert C, et al. (2010) [Contraception, therapeutic abortion, and pulmonary arterial hypertension]. Presse Med 39: 1S46-50.

14. Thorne S, Nelson-Piercy C, MacGregor A, Gibbs S, Crowhurst J, et al (2006) Pregnancy and contraception in heart disease and pulmonary arterial hypertension. J Fam Plann Reprod Health Care 32: 75-81.

15. Kiely DG, Condliffe R, Webster V, Mills GH, Wrench I, et al. (2010) Improved survival in pregnancy and pulmonary hypertension using a multiprofessional approach. BJOG 117: 565-574.
16. Duarte AG, Thomas S, Safdar Z, Torres F, Pacheco LD, et al. (2013) Management of pulmonary arterial hypertension during pregnancy: a retrospective, multicenter experience. Chest 143: 1330-1336.

17. Berger G, Azzam ZS, Hoffman R, Yigla M (2009) Coagulation and anticoagulation in pulmonary arterial hypertension. Isr Med Assoc J 11: 376-379.

18. Jaïs X, Olsson KM, Barbera JA, Blanco I, Torbicki A, et al. (2012) Pregnancy outcomes in pulmonary arterial hypertension in the modern management era. Eur Respir J 40: 881-885.

19. Rich S, Kaufmann E, Levy PS (1992) The effect of high doses of calciumchannel blockers on survival in primary pulmonary hypertension. N Engl J Med 327: 76-81.

20. Humbert M, Sitbon O, Simonneau G (2004) Treatment of pulmonary arterial hypertension. N Engl J Med 351: 1425-1436.

21. O'Callaghan DS, Savale L, Yaïci A, Natali D, Jaïs X, et al. (2011) Endothelin receptor antagonists for the treatment of pulmonary arterial hypertension. Expert Opin Pharmacother 12: 1585-1596.

22. Archer SL, Michelakis ED (2009) Phosphodiesterase type 5 inhibitors for pulmonary arterial hypertension. N Engl J Med 361: 1864-1871.

23. Strauss WL, Edelman JD (2007) Prostanoid therapy for pulmonary arteria hypertension. Clin Chest Med 28: 127-142.

24. Channick RN (2013) Combination therapy in pulmonary arterial hypertension. Am J Cardiol 111: 16C-20C.

25. McLaughlin VV, Archer SL, Badesch DB, Barst RJ, Farber HW, et al. (2009) ACCF/AHA 2009 expert consensus document on pulmonary hypertension a report of the American College of Cardiology Foundation Task Force on Expert Consensus Documents and the American Heart Association developed in collaboration with the American College of Chest Physicians; American Thoracic Society, Inc.; and the Pulmonary Hypertension Association. J Am Coll Cardiol 53: 1573-1619.

26. Siu SC, Sermer M, Colman JM, Alvarez AN, Mercier LA, et al. (2001) Prospective multicenter study of pregnancy outcomes in women with heart disease. Circulation 104: 515-521.

27. Uebing A, Steer PJ, Yentis SM, Gatzoulis MA (2006) Pregnancy and congenital heart disease. BMJ 332: 401-406.

28. Monnery L, Nanson J, Charlton G (2001) Primary pulmonary hypertension in pregnancy; a role for novel vasodilators. Br J Anaesth 87: 295-298.

29. Bonnin M, Mercier FJ, Sitbon O, Roger-Christoph S, Jaïs X, et al. (2005) Severe pulmonary hypertension during pregnancy: mode of delivery and anesthetic management of 15 consecutive cases. Anesthesiology 102: 1133-1137.

30. Chamaidi A, Gatzoulis MA (2006) Heart disease and pregnancy. Hellenic J Cardiol 47: 275-291. 
Citation: Rosengarten D, Kramer MR (2013) Pulmonary Hypertension and Pregnancy: Management and Outcome. J Pulmon Resp Med S4: 004. doi:10.4172/2161-105X.S4-004

31. Rosengarten D, Blieden LC, Kramer MR (2012) Pregnancy outcomes in pulmonary arterial hypertension in the modern management era. Eur Respir J 40: $1304-1305$
32. Smith JS, Mueller J, Daniels CJ (2012) Pulmonary arterial hypertension in the setting of pregnancy: a case series and standard treatment approach. Lung 190: $155-160$

This article was originally published in a special issue, Pulmonary Hypertension handled by Editor(s). Dr. Zeenat Safdar, Baylor College of Medicine, United States 